\title{
Rhodanine side-chained thiophene and indacenodithiophene copolymer for solar cell applications
}

\author{
Meijie Fan ${ }^{\text {a, b }}$, Linrui Duan ${ }^{\mathrm{b}}$, Yuanhang Zhou ${ }^{\mathrm{b}}$, Shuguang Wen ${ }^{\mathrm{b}}$, Feng Li ${ }^{\mathrm{c}}$, Deyu Liu ${ }^{\mathrm{b}}$, \\ Mingliang Sun ${ }^{a,}$, Renqiang Yang ${ }^{b}$ \\ a Institute of Materials Science and Engineering, Ocean University of China, Qingdao 266100, China \\ b CAS Key Laboratory of Bio-Based Materials, Qingdao Institute of Bioenergy and Bioprocess Technology, Chinese Academy of Sciences, Qingdao 266101, \\ China \\ ${ }^{\mathrm{c}}$ Key Laboratory of Rubber-Plastics of Ministry of Education/Shandong Province, School of Polymer Science and Engineering, Qingdao University of Science \\ \& Technology, 53 Zhengzhou Road, Qingdao 266042, China
}

\section{A R T I C L E I N F O}

\section{Article history:}

Received 14 April 2017

Received in revised form 10 June 2017

Accepted 9 July 2017

Available online 19 July 2017

\section{Keywords:}

Polymer solar cells

Side chain

Indacenodithiophene

Rhodanine

\begin{abstract}
A B S T R A C T
In this work, 2-(3-ethyl-4-oxothiazolidin-2-ylidene)malononitrile is connected on the $\beta$ position of thiophene, and this monomer is copolymerized with indacenodithiophene (IDT) to build one novel photovoltaic polymer (PIDTPCR). The highest occupied molecular orbital (HOMO) and the lowest unoccupied molecular orbital (LUMO) level of the polymer is $-5.26 \mathrm{eV}$ and $-3.45 \mathrm{eV}$, respectively. Compared with reference polymer without rhodanine side chain, PIDTPCR polymer shows low band gap and low energy level which contribute to the $\mathrm{J}_{\mathrm{sc}}$ and $\mathrm{V}_{\mathrm{oc}}$ of the PSCs devices. The best performance parameters of the solar cells devices are $\mathrm{V}_{\mathrm{oc}}(0.91 \mathrm{~V})$, $\mathrm{J}_{\mathrm{sc}}\left(10.1 \mathrm{~mA} / \mathrm{cm}^{2}\right)$, FF $(52.4 \%)$ and PCE $(5.18 \%)$.
\end{abstract}

() 2017 Elsevier Ltd. All rights reserved.

\section{Introduction}

Polymer solar cells (PSCs) have drawn a great deal of attention due to their unique features for low cost, easy processing, low weight, flexibility, and large-area fabrication [1-5]. It is an efficient strategy using donor-acceptor (D-A) copolymer to optimize the photovoltaic polymers properties [6,7], because D-A copolymer can form an intramolecular charge transfer (ICT) state which widen the polymer light absorption. The strength of ICT state varies with different donor and accepter units, so the changes of donor and accepter units can optimize polymers photovoltaic performances [8]. Through donor and accepter design, the polymer optical band gap match well with solar spectrum and the energy levels match with that of PCBM, and then the PSCs devices performance can be improved [9]. Therefore, appropriate donor and acceptor units play a very essential role in $\mathrm{D}-\mathrm{A}$ polymer design. On this basis, many

\footnotetext{
* Corresponding author.

E-mail addresses: mlsun@ouc.edu.cn (M. Sun), yangrq@qibebt.ac.cn (R. Yang).
}

novel donor-acceptor (D-A) conjugated copolymers have been widely developed and applied to PSCs with PCE over 12\% [10-14].

Indacenodithiophene (IDT) with highly planar structure has been demonstrated as a promising build block for polymer donor materials because of its extraordinary electron-donating and hole transporting performance $[15,16]$. IDT based conjugated polymers were widely applied in PSCs and showed broad absorption and high molar extinction coefficient, which is beneficial to obtaining high short circuit current $\left(\mathrm{J}_{\mathrm{sc}}\right)[17,18]$. The solubility of IDT polymer can be easily increased by attaching functional side chains due to the effect of sp3-hybridized carbon atoms on the IDT $[16,19,20]$. Rhodanine, as an electron withdrawing unit, can effectively induce intramolecular charge transfer and improve optical absorption properties. Rhodanine is widely used as end capping group in photovoltaic small molecule, while there is very few report about rhodanine used in photovoltaic polymer [21-23]. As an alternative method to design D-A polymer with donor and acceptor unit both in polymer backbone, electron deficient side chains introduced to polymer backbone can also effectively broaden absorption spectrum and deepen energy levels [24]. This method has been proved to be successful in many polymer systems [25-28]. 
In this work, we have synthesized a polymer based on IDT and 2(5-((2,5-dibromothiophene-3-yl)methylene)-3-ethyl-4-oxothiazolidin-2-ylidene)malononitrile units to investigate the influence of rhodanine side chain on the thiophene and IDT backboned polymer. We have compared our test results with the polymer based IDT and thiophene in literature without rhodanine side chain [29]. The introduction of rhodanine side chain can widen absorption spectrum; and the highest occupied molecular orbital energy level (HOMO) and the lowest unoccupied molecular orbital energy level (LUMO) of the resulted polymer have been deepened. As a result of the deep energy levels, the best open circuit voltage $\left(\mathrm{V}_{\mathrm{oc}}\right)$ of PSCs devices is $0.91 \mathrm{~V}$ and the PCE has also been improved accordingly.

\section{Experimental}

All of the reagents were purchased from commercial sources. They did not need further purification before used, unless otherwise noted. Toluene and diethyl ether were dried by sodium, and benzophenone was used as indicator. $\mathrm{N}, \mathrm{N}$-dimethylformamine (DMF) was distilled with calcium hydride. 2-(3-Ethyl-4oxothiazolidin-2-ylidene)malononitrile was synthesized in our laboratory. Indacenodithiophene was purchased from Derthon optoelectronic materials science technology co. LTD.

\subsection{Instruments}

NMR spectra were measured on a Bruker Advance III60 Spectrometer. Gel permeation chromatography (GPC) on a HLC-8320 instrument was used to obtain the molecular weights of the polymer; tetrahydrofuran (THF) was used as eluent; polystyrenes were used as reference. The Ultraviolet-visible (UV-vis) absorption spectra were recorded on a Lambda 25 spectrophotometer. The thermogravimetric analysis (TGA) was characterized with SDTQ600 instrument under nitrogen atmosphere. Cyclic voltammetry (CV) was estimated by a CHI660D electrochemical workstation. Three-electrode system consists of glassy carbon working electrode, Pt wire counter electrode and saturated calomel reference electrode. The test was performed under tetrabutylammonium phosphorus hexafluoride $\left(\mathrm{Bu}_{4} \mathrm{NPF}_{6}, 0.1 \mathrm{M}\right)$ in acetonitrile solution as the supporting electrolyte, with the scan rate of $100 \mathrm{mV} / \mathrm{s}$ and ferrocene/ferrocenium $\left(\mathrm{Fc} / \mathrm{Fc}^{+}\right)$as the internal standard. AFM studies were conducted on an Agilent 5400 instrument. X-ray diffraction (XRD) pattern was determined with a Bruker D8 Advance.

\subsection{Device fabrication}

Photovoltaic devices were fabricated in the structure of ITO/ PEDOT:PSS (30 nm)/polymer:PCBM/PFN/Al (100 nm). ITO coated glass substrates are cleaned with ITO lotion, distilled water, acetone and isopropyl alcohol sequentially. Then the ITO coated glass substrates were treated by oxygen plasma. PEDOT:PSS were spincoated on the ITO substrates. Then polymer and $\mathrm{PC}_{71} \mathrm{BM}$ were blended in o-dichlorobenzene in the ratio of $1: 1,1: 2,1: 3$ and 1:4. The prepared solutions were stirred overnight in glove box. The polymer and $\mathrm{PC}_{71} \mathrm{BM}$ blends were spin-coated on the ITO/ PEDOT:PSS substrates. Then PFN was spin-coated on the top of the active layer from absolute methanol solution with concentration around $0.2 \mathrm{mg} / \mathrm{mL}$, and the final PFN thickness was around $5 \mathrm{~nm}$. Finally, Al was thermally evaporated on the top of PFN. Photovoltaic performances were obtained under the illumination of AM $1.5 \mathrm{G}$ $\left(100 \mathrm{mWcm}^{-2}\right)$ in nitrogen atmosphere. J-V data were collected by a Keithley 2420 source meter.

\subsection{Synthesis}

\subsubsection{Thiophene-3-carbaldehyde}

A solution of 3-bromothiophene $(10 \mathrm{~g}, 61.3 \mathrm{mmol})$ in $60 \mathrm{~mL}$ of dried diethyl ether was cooled to $-78^{\circ} \mathrm{C}$, and then $27 \mathrm{~mL}$ of n-butyl lithium (2.5 $\mathrm{M}$ in hexane, $67.5 \mathrm{mmol}$ ) was added dropwise. The reaction mixture was stirred for $1 \mathrm{~h}$. Subsequently, a solution of $\mathrm{N}, \mathrm{N}$-dimethylformamine (DMF, $6.72 \mathrm{~g}, 92 \mathrm{mmol}$ ) in $20 \mathrm{~mL}$ of diethyl ether was added dropwise. The reaction mixture was kept at $-78{ }^{\circ} \mathrm{C}$ for additional $30 \mathrm{~min}$ and then the mixture was warmed to room temperature. The reaction was stirred for $45 \mathrm{~min}$ at ambient temperature and then quenched by water. The mixture was extracted with diethyl ether. The organic phase was dried over anhydrous sodium sulfate and concentrated via rotary evaporation. The residue was purified by silica gel chromatography with an eluent of dichloromethane/hexanes $(1 / 2)$ to obtain a product $(5.59 \mathrm{~g}, 81.3 \%)$ as a yellow oil. ${ }^{1} \mathrm{H}$ NMR $\left(600 \mathrm{MHz}, \mathrm{CDCl}_{3}\right) \delta(\mathrm{ppm})$ $9.93(\mathrm{~s}, 1 \mathrm{H}), 8.13(\mathrm{~d}, 1 \mathrm{H}), 7.54(\mathrm{~d}, 1 \mathrm{H}), 7.38(\mathrm{dd}, 1 \mathrm{H})$.

\subsubsection{2,5-Dibromothiophene-3-carbaldehyde [30]}

A solution of thiophene-3-carboxaldehyde (3.6 g, $32.1 \mathrm{mmol}$ ) in $30 \mathrm{~mL}$ of dried N,N-dimethylformamine (DMF) was stirred at room temperature in dark. A solution of N-bromosuccinimide (NBS) (17.14 g, $96.3 \mathrm{mmol}$ ) in $33 \mathrm{~mL}$ of DMF was added dropwise. The mixture was stirred for $48 \mathrm{~h}$. The reaction was finished, and the solution was quenched with water and extracted several times with diethyl ether. The organic phases were collected and dried with anhydrous $\mathrm{Na}_{2} \mathrm{SO}_{4}$. After evaporation, the concentrated part was purified by column chromatography with an eluent of dichloromethane/hexanes (1/1). After removal of solvent, the product was recrystallized from n-hexane. A yellow crystalline solid was obtained. ${ }^{1} \mathrm{H} \mathrm{NMR}\left(600 \mathrm{MHz}, \mathrm{CDCl}_{3}\right) \delta(\mathrm{ppm}) 9.80(\mathrm{~s}, 1 \mathrm{H}), 7.34(\mathrm{~s}, 1 \mathrm{H})$.

\subsubsection{2-(5-((2,5-Dibromothiophen-3-yl)methylene)-3-ethyl-4- oxothiazolidin-2-ylidene)malononitrile [31]}

A mixture of 2,5-dibromothiophene-3-carbaldehyde $(500 \mathrm{mg}$, $1.85 \mathrm{mmol}$ ), 2-(3-ethyl-4-oxothiazolidin-2-ylidene)malononitrile (715.8 $\mathrm{mg}, 3.7 \mathrm{mmol}$ ), and basic aluminum oxide (1.03 g) reacted in dry toluene $(50 \mathrm{~mL})$ at $70{ }^{\circ} \mathrm{C}$ for $3 \mathrm{~h}$ and cooled to ambient temperature. The filtrate was collected by filtration and the residue thoroughly was washed with toluene. The solvent of the filtrate was removed by evaporation, and the crude product was purified by column chromatography on silica with $\mathrm{CH}_{2} \mathrm{Cl}_{2}$ to give a green yellow solid (499 mg, 60\%). ${ }^{1} \mathrm{H}$ NMR (600 MHz, CDCl 3 ) $\delta(\mathrm{ppm}) 7.83$ (s, $1 \mathrm{H}), 7.26(\mathrm{~s}, 1 \mathrm{H}), 4.33(\mathrm{q}, 2 \mathrm{H}), 1.42(\mathrm{t}, 3 \mathrm{H}) .{ }^{13} \mathrm{CNMR}\left(151 \mathrm{MHz}, \mathrm{CDCl}_{3}\right)$ $\delta(\mathrm{ppm}) 165.90,164.80,134.45,127.61,126.99,121.78,117.94,114.59$, 112.81, 111.76, 56.79, 40.88, 14.16. HRMS (EI) calcd for $\mathrm{C}_{13} \mathrm{H}_{7} \mathrm{Br}_{2} \mathrm{~N}_{3} \mathrm{OS}_{2}[\mathrm{M}+\mathrm{H}]+:$ : 445.15, found: 445.00 .

\subsubsection{Synthesis of PIDTPCR}

Indacenodithiophene-Sn (184.95 mg, $0.15 \mathrm{mmol}), 2-(5-((2,5-$ dibromothiophene-3-yl)methylene)-3-ethyl-4-oxothiazolidin-2ylidene)malononitrile $(66.77 \mathrm{mg}, 0.15 \mathrm{mmol}), \mathrm{Pd}_{2}(\mathrm{dba})_{3}(4.12 \mathrm{mg}$, $0.0045 \mathrm{mmol})$, and tri(o-tolyl)phosphine $(8.24 \mathrm{mg}, 0.027 \mathrm{mmol})$ were added in a $25 \mathrm{~mL}$ flask. The system was purged with nitrogen for three times. After the addition of toluene $(5 \mathrm{~mL})$, the mixture was heated to $115{ }^{\circ} \mathrm{C}$ and maintained for $48 \mathrm{~h}$ under nitrogen protection. After cooling to ambient temperature, the mixture was precipitated into methanol and collected by filtration. The polymer was dealt with a Soxhlet funnel and extracted by acetone, hexane and chloroform, 
successively. The part of chloroformic solution was collected and dried. The polymer PIDTPCR was obtained (170 mg, 67\%). ${ }^{1} \mathrm{H}$ NMR $\left(600 \mathrm{MHz}, \mathrm{CDCl}_{3}\right) \delta$ 7.50-7.41 (m, 2H), 7.20-7.05 (m, 20H), 4.34 (dr, $2 \mathrm{H}), 2.57(\mathrm{dr}, 8 \mathrm{H}), 1.59-0.87(\mathrm{~m}, 47 \mathrm{H})$. Elemental analysis calcd (\%) for $\left[\mathrm{C}_{79} \mathrm{H}_{85} \mathrm{~N}_{3} \mathrm{OS}_{4}\right]$ : C 77.72\%, H 7.02\%, N 3.44\%; found: C 76.84\%, H 6.79\%, $\mathrm{N} 3.46 \%$.

\section{Results and discussion}

\subsection{Synthesis and characterization}

The polymer PIDTPCR was synthesized by stille coupling reactions as shown in Scheme 1. The side chains on the IDT ensure that PIDTPCR was readily dissolved in chloroform, chlorobenzene and o-dichlorobenzene. The number-average molecular $\left(M_{n}\right)$ of PIDTPCR is $12 \mathrm{KDa}$ with a polydispersity index (PDI) of 1.32 measured by gel permeation chromatography (GPC). Thermal gravity analysis (TGA) measurement demonstrated that the decomposition temperature $\left(\mathrm{T}_{\mathrm{d}}\right)$ of the polymer is $389.1{ }^{\circ} \mathrm{C}$. The polymer possesses good thermal stability. The TGA curve is exhibited in Fig. 1.

\subsection{UV-vis absorption and electrochemical properties}

The UV-visible absorption spectra of PIDTPCR in diluted chloroform solution and in thin film were exhibited in Fig. 2. The short wavelength absorption of the polymer was showed at around $365 \mathrm{~nm}$ corresponding to the delocalized excitonic $\pi-\pi^{*}$ transitions [32]. The long wavelength absorption of the polymer was presented at around $450 \mathrm{~nm}-650 \mathrm{~nm}$ originated from intramolecular charge transfer (ICT) between the acceptor and donor units [33]. Compared with the UV-visible absorption spectra in solution, the absorption peak of the film is broad due to the intensive intermolecular interactions [34]. Based on the absorption onsets of the thin films, the optical band gap $\left(\mathrm{E}_{\mathrm{g}}^{\mathrm{opt}}\right)$ is calculated to be $1.81 \mathrm{eV}$. Compared with the previous reported polymer without rhodanine side chain [29], the absorption onset is extended from $590 \mathrm{~nm}$ to $685 \mathrm{~nm}$ in the film. There are two possible reasons lead to this result. One is the vinylene linkage of PIDTPCR polymer promotes the coplanarity and increases conjugation [25]. The other is the intramolecular charge transfer (ICT) between the

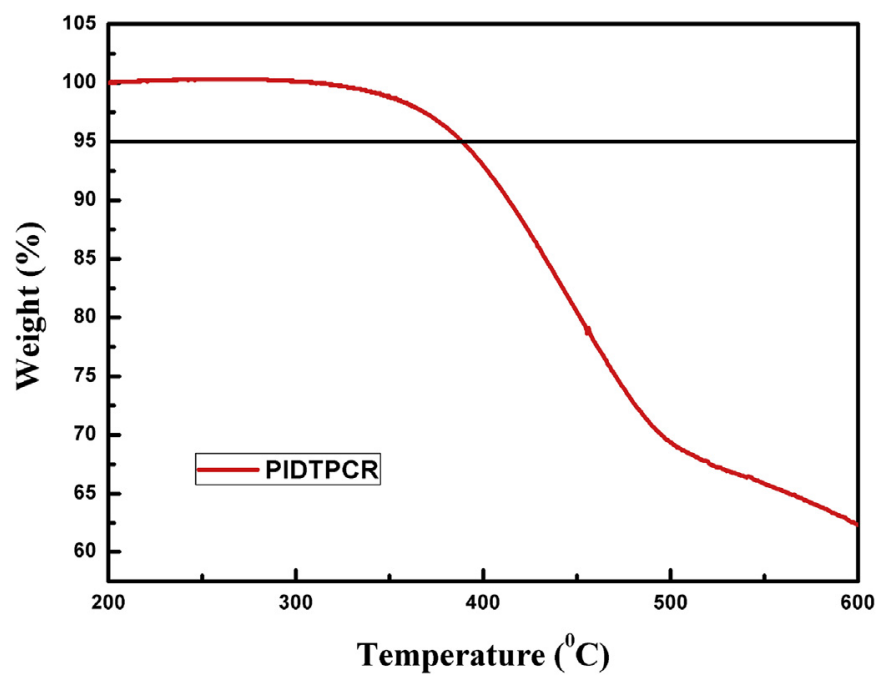

Fig. 1. TGA of PIDTPCR polymer.

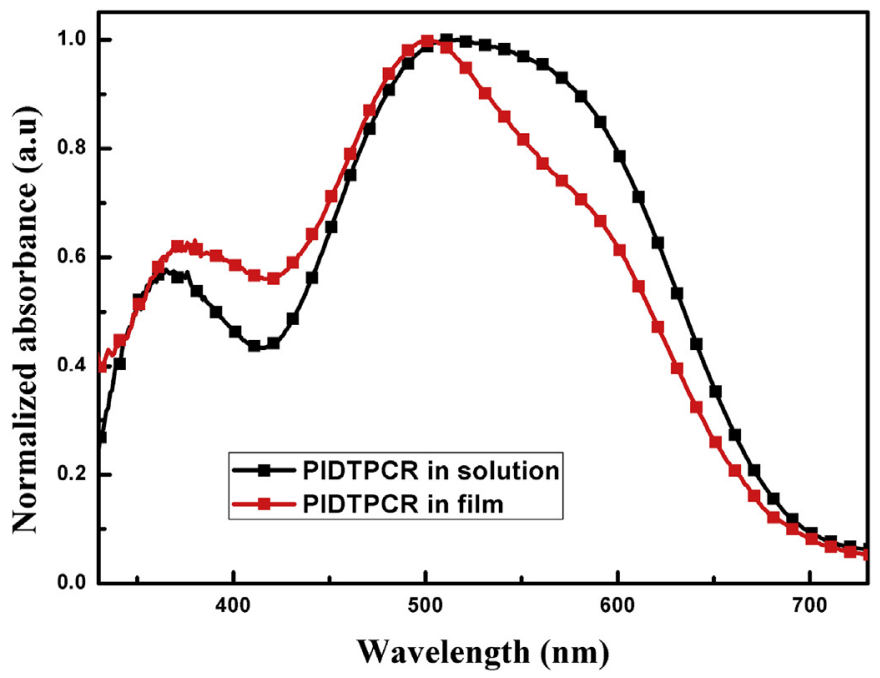

Fig. 2. UV-vis absorption spectra of PIDTPCR in chloroform solution and in thin film.

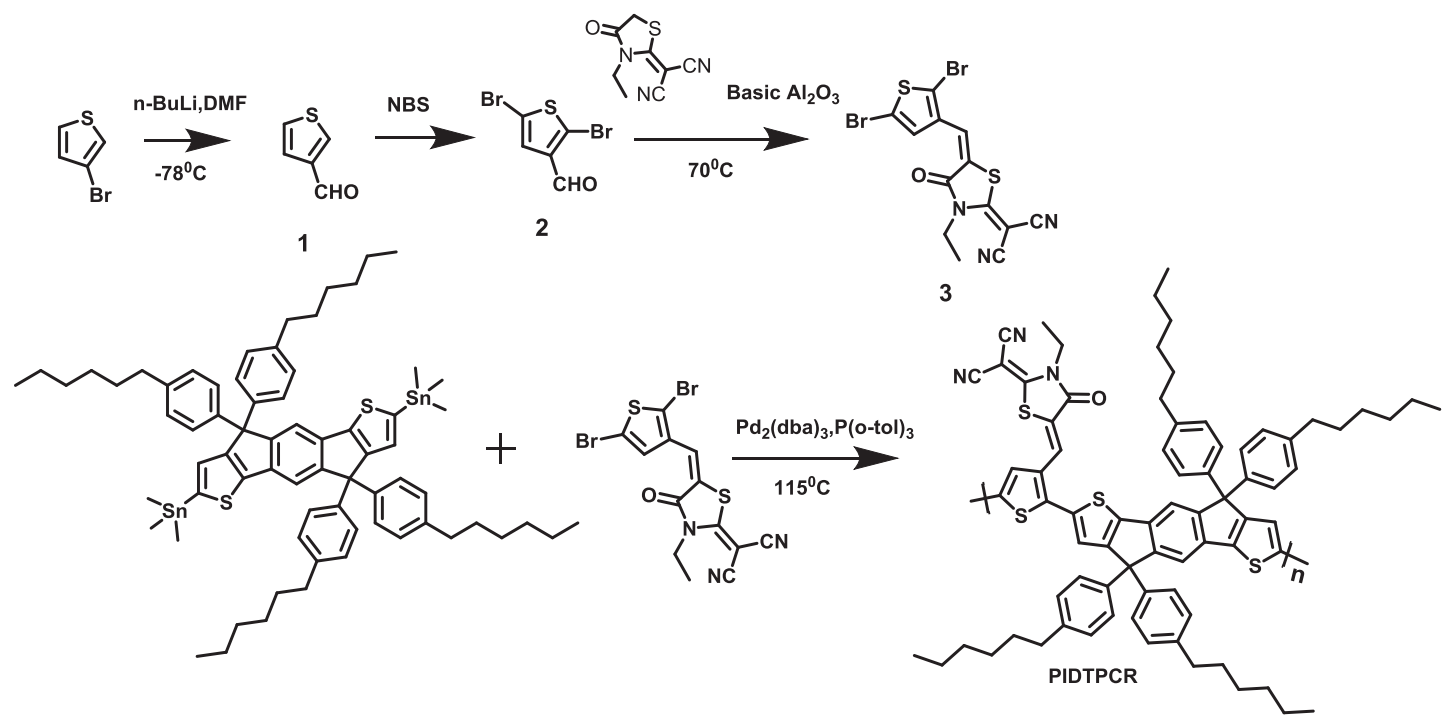

Scheme 1. Synthetic routes for the polymer. 
Table 1

Molecular weights, optical and electrochemical properties of PIDTPCR and reference polymer.

\begin{tabular}{|c|c|c|c|c|c|c|}
\hline Polymer & $M_{\mathrm{w}}(\mathrm{PDI})$ & $\lambda_{\max }($ film $)$ & $E_{\mathrm{g}}^{\mathrm{opt}}(\mathrm{eV})$ & HOMO $(\mathrm{eV})$ & LUMO (eV) & Ref \\
\hline P3 & $48,700(2.19)$ & 510 & 2.08 & -5.1 & -3.02 & [29] \\
\hline PIDTPCR & $16,700(1.32)$ & 511 & 1.81 & -5.26 & -3.45 & \\
\hline
\end{tabular}

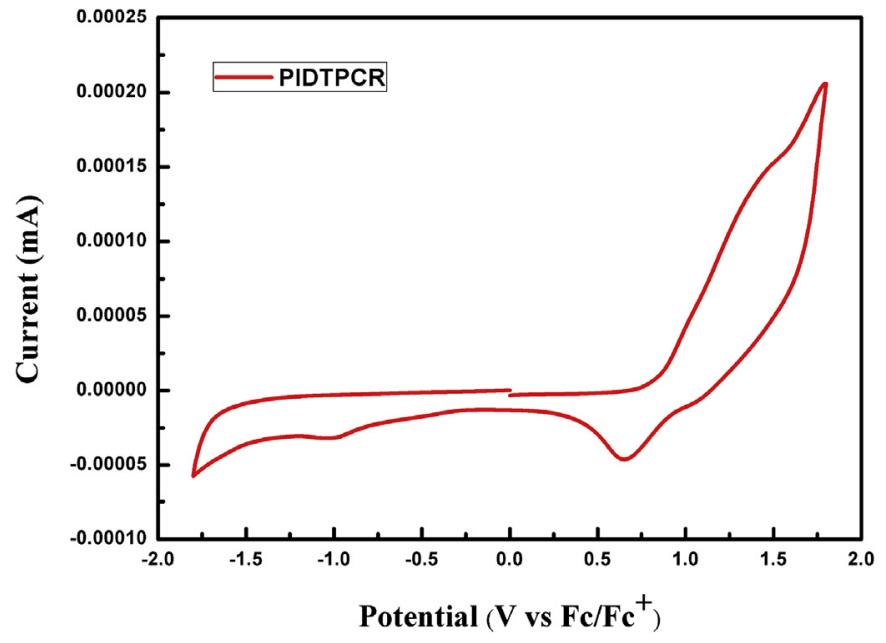

Fig. 3. Cyclic voltammogram of the polymer film.

electron-accepting side chain and electron-donating main chain [26]. And the related data were listed in Table 1.

The electrochemical property of PIDTPCR was demonstrated by the electrochemical cyclic voltammetry (CV). The CV curve was

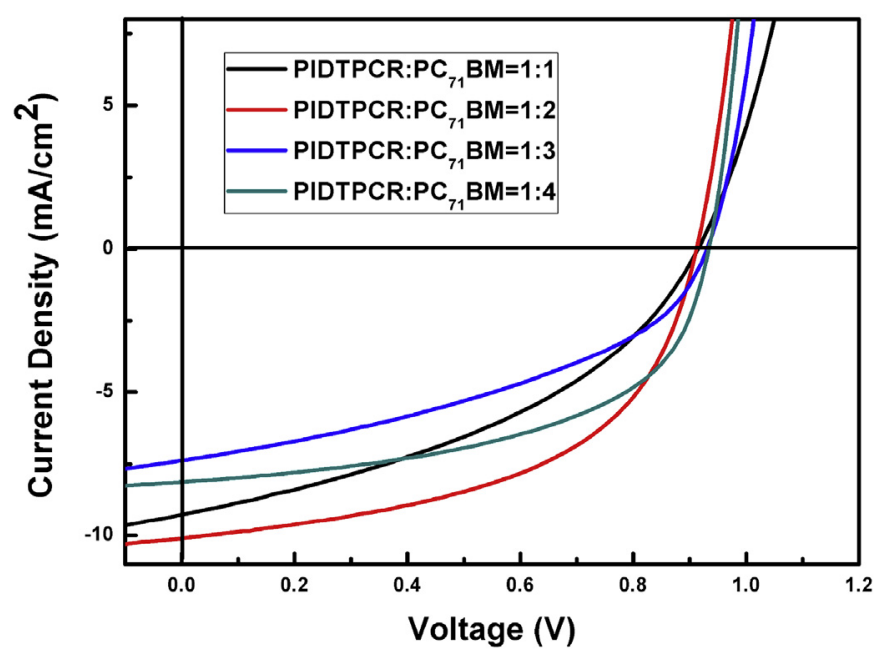

Fig. 4. $\mathrm{J}-\mathrm{V}$ curves of PSCs devices under the illumination of $\mathrm{AM} 1.5 \mathrm{G}, 100 \mathrm{mWcm}^{-2}$. shown in Fig. 3. And the onset oxidation potential $\left(\mathrm{E}_{\mathrm{ox}}\right)$ is $0.85 \mathrm{~V}$. The HOMO was $-5.26 \mathrm{eV}$ obtained by the equations: $\mathrm{HOMO}=-\left(\mathrm{E}_{\mathrm{Ox}}+4.41\right)(\mathrm{eV})$, according to the energy level of the $\mathrm{F}_{\mathrm{c}} /$ $\mathrm{F}_{\mathrm{C}}^{+}$versus saturated calomel electrode (SCE). The LUMO was $-3.45 \mathrm{eV}$ estimated by the HOMO level and optical band gap. The energy level of PIDTPCR is deeper than the polymer based on IDT and thiophene without rhodanine side chain, and these results were compared in Table 1 [29]. The deep HOMO energy level of the polymer will lead to higher PSCs $\mathrm{V}_{\mathrm{oc}}$.

\subsection{Photovoltaic performance}

To characterize photovoltaic properties of PIDTPCR, PSCs devices were prepared in a configuration of ITO/PEDOT:PSS(30 nm)/ polymer: $\mathrm{PC}_{71} \mathrm{BM}(120 \mathrm{~nm}) / \mathrm{PFN}(5 \mathrm{~nm}) / \mathrm{Al}(100 \mathrm{~nm})$. To obtain the optimized devices, the PIDTPCR:PC ${ }_{71} \mathrm{BM}$ blend ratios were adjusted from $1: 1$ to $1: 4$, and the concentration of blends in o-dichlorobenzene is $30 \mathrm{mg} / \mathrm{mL}$. The best performance parameters of the devices are $\mathrm{V}_{\mathrm{oc}}(0.91 \mathrm{~V}), \mathrm{J}_{\mathrm{sc}}\left(10.1 \mathrm{~mA} / \mathrm{cm}^{2}\right), \mathrm{FF}(52.4 \%)$ and PCE (5.18\%) with a PIDTPCR:PC 71 BM weight ratio of $1: 2$. The J-V curves of PSCs devices with the different weight ratios were shown in Fig. 4. We have compared the optimal performances of the polymer with other report about the polymer based on IDT and thiophene units without rhodanine side chain [29]. And the comparison data were listed below as Table 2. To highlight the high $\mathrm{V}_{\mathrm{oc}}$, the donor photon energy loss defined as $\mathrm{E}_{\mathrm{g}}-\mathrm{eV}_{\mathrm{oc}}$ was introduced [35], where $E_{g}$ is the optical band gap of the polymer. The value of $E_{g}-e_{o c}$ for PIDTPCR is $0.9 \mathrm{eV}$, while the value of $\mathrm{E}_{\mathrm{g}}-\mathrm{eV}_{\mathrm{oc}}$ for P3 is $1.28 \mathrm{eV}$. The PIDTPCR based devices show lower energy loss, so the introduction of the rhodanine side chain can improve the photovoltaic performance. The external quantum efficiency (EQE) curve has been measured to verify the accuracy of the device performances under the optimal conditions and shown in Fig. 5. The PSCs device absorbs sunlight from $319 \mathrm{~nm}$ to $700 \mathrm{~nm}$, and the maximum incident photon to current efficiency appears at $439 \mathrm{~nm}$. The $\mathrm{J}_{\mathrm{sc}}$ calculated from EQE matched with the $\mathrm{J}_{\mathrm{sc}}$ measured by J-V curve (within $5 \%$ error). Compared with P3, the device of PIDTPCR has a broader photo response range and the maximum IPCE show improvement. These contribute to the larger $\mathrm{J}_{\text {sc. }}$. Hole mobility was characterized by the space-charge-limited current (SCLC) method. The device structure is ITO/PEDOT:PSS/PIDTPCR:PC ${ }_{71} \mathrm{BM} / \mathrm{Ag}$. The test result calculated by Mott-Gumey equation was $7.0 \times 10^{-4} \mathrm{~cm}^{2} \mathrm{~V}^{-1} \mathrm{~s}^{-1}$. The FF of PIDTPCR based PSCs devices (Table 2) was slightly lower than P3 (reference polymer), and the relative low hole mobility of PIDTPCR may be one possible reason. The SCLC curve was plotted in Fig. 6.

Table 2

PSCs devices performances.

\begin{tabular}{|c|c|c|c|c|c|c|}
\hline Polymer & Polymer:PC ${ }_{71} \mathrm{BM}$ & $J_{\mathrm{sc}}\left(\mathrm{mA} / \mathrm{cm}^{2}\right)$ & $V_{\mathrm{oc}}(\mathrm{V})$ & $\mathrm{FF}$ & PCE (\%) & Ref \\
\hline P3 & $1: 3$ & 7.6 & 0.80 & 0.54 & 3.3 & [29] \\
\hline PIDTPCR & $1: 1$ & $9.26(8.85)$ & $0.91(0.93)$ & $0.40(0.38)$ & 3.67 (3.39) & This work \\
\hline PIDTPCR & $1: 2$ & $10.1(9.72)$ & $0.91(0.92)$ & $0.52(0.51)$ & $5.18(4.89)$ & This work \\
\hline PIDTPCR & $1: 3$ & $7.07(7.22)$ & $0.94(0.93)$ & $0.44(0.43)$ & 3.15 (3.09) & This work \\
\hline PIDTPCR & $1: 4$ & $8.12(8.08)$ & $0.93(0.92)$ & $0.54(0.53)$ & $4.38(4.23)$ & This work \\
\hline
\end{tabular}

Values in parentheses are average data from 6 devices. 


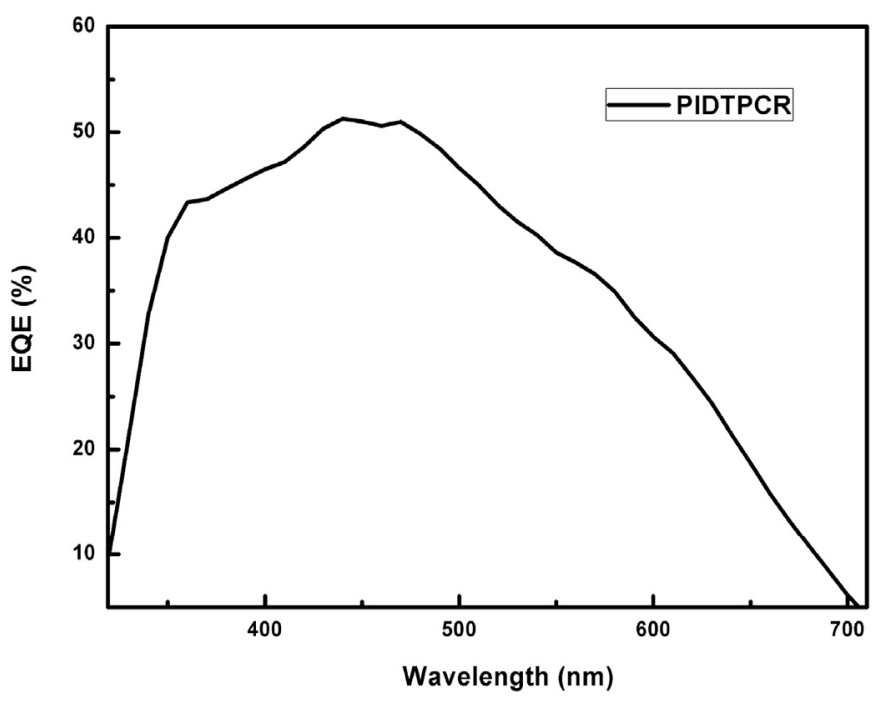

Fig. 5. EQE curve of the best PCE device.

\subsection{Morphological properties}

The topography of active layer is a crucial factor for PSCs device properties. Atomic force microscope (AFM) was used to explore the active layer's morphology and the surface topography was

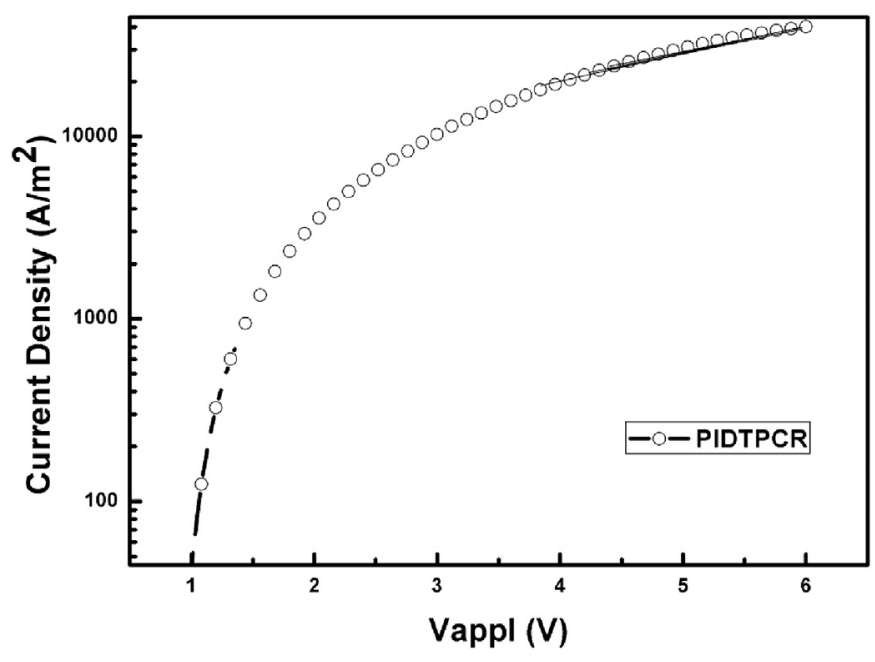

Fig. 6. SCLC characteristics of PIDTPCR.

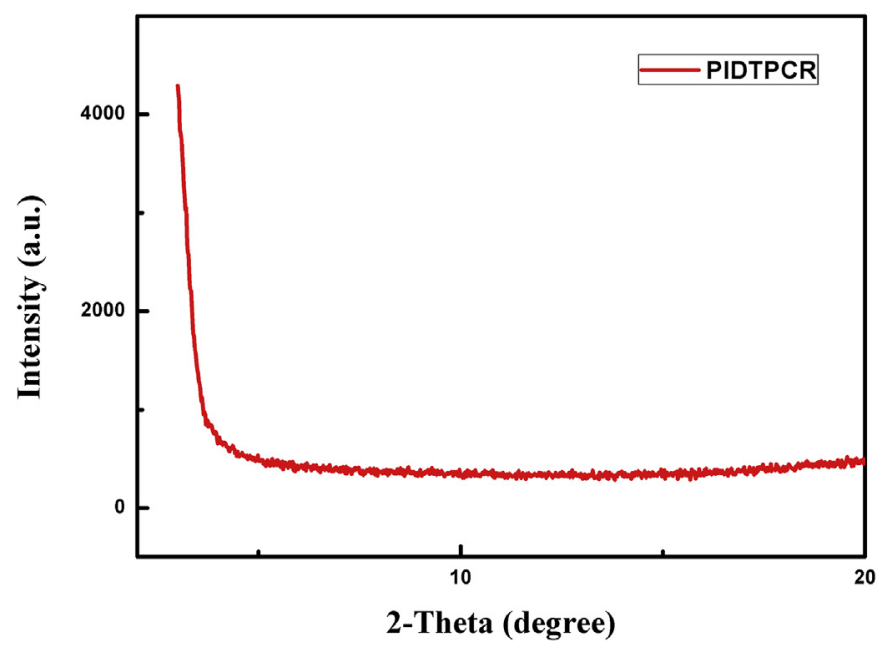

Fig. 8. XRD pattern of the polymer thin film.

exhibited in Fig. 7. The root-mean-square roughness was around $1 \mathrm{~nm}$. The active layer has formed good interpenetrating network structure and appropriate phase separation [36]. This structure contributes to the improvement of JSC and FF, so that the PCE can be enhanced. In order to analysis the crystallinity of the polymer, X-ray diffraction (XRD) test were carried out. From Fig. 8, we can conclude that the polymer is amorphous.

\section{Conclusion}

In summary, we have successfully introduced 2-(3-ethyl-4oxothiazolidin-2-ylidene) malononitrile to the $\beta$ position of thiophene to build one new monomer for IDT polymer. Compared with the polymer without rhodanine side-chain, the UV-vis absorption and EQE photo response of the new polymer have been broadened. The energy levels were deepened. The PSCS PCE was improved to $5.18 \%$ with $\mathrm{V}_{\mathrm{oc}}(0.91 \mathrm{~V})$, $\mathrm{J}_{\mathrm{sc}}\left(10.1 \mathrm{~mA} / \mathrm{cm}^{2}\right)$ and $\mathrm{FF}(52.4 \%)$. The novel monomer is a promising unit in polymer solar cell donor materials design.

\section{Acknowledgements}

The authors gratefully acknowledge financial support from the NSFC (51573205 and 21274134).
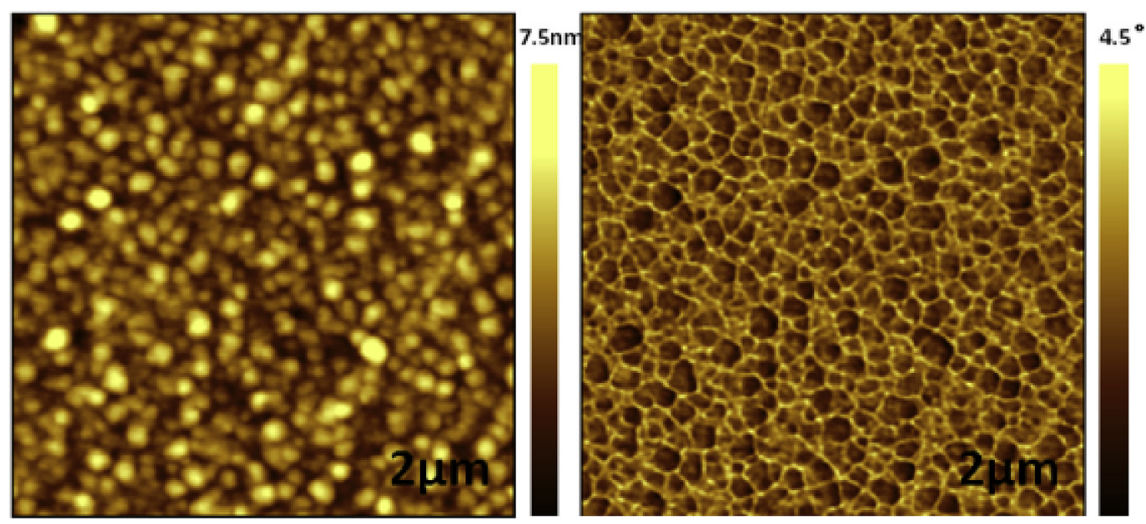

Fig. 7. AFM image of PSCs active layer (topography and phase) $(2 \times 2 \mu \mathrm{m})$. 


\section{References}

[1] J.G.G. Yu, J.C. Hummelen, F. Wudl, A.J. Heeger, Science 270 (1995) 1789-1791. 2] S. Gunes, H. Neugebauer, N.S. Sariciftci, Chem. Rev. 107 (2007) 1324-1338.

[3] E. Zhou, S. Yamakawa, K. Tajima, C. Yang, K. Hashimoto, Chem. Mater. 21 (2009) 4055-4061.

[4] Z. He, C. Zhong, X. Huang, W.Y. Wong, H. Wu, L. Chen, S. Su, Y. Cao, Adv. Mater. 23 (2011) 4636-4643.

[5] M. Fan, Z. Du, W. Chen, D. Liu, S. Wen, M. Sun, R. Yang, Asian J. Org. Chem. 5 (2016) 1273-1279.

[6] D. Liu, C. Gu, M. Xiao, M. Qiu, M. Sun, R. Yang, Polym. Chem. 6 (2015) 3398-3406.

[7] P. Peumans, A. Yakimov, S.R. Forrest, J. Appl. Phys. 93 (2003) 3693-3723.

8] Y.J. Cheng, S.H. Yang, C.S. Hsu, Chem. Rev. 109 (2009) 5868-5923.

[9] J.W. Lee, H. Ahn, W.H. Jo, Macromolecules 48 (2015) 7836-7842.

[10] Z.C. He, C.M. Zhong, S.J. Su, M. Xu, H.B. Wu, Y. Cao, Nat. Photonics 6 (2012) $591-595$.

[11] J.D. Chen, C. Cui, Y.Q. Li, L. Zhou, Q.D. Ou, C. Li, Y. Li, J.X. Tang, Adv. Mater. 27 (2015) 1035-1041.

[12] D. Ding, W. Chen, J. Wang, M. Qiu, H. Zheng, J. Ren, M. Fan, M. Sun, R. Yang, J. Mater. Chem. C 4 (2016) 8716-8723.

[13] W. Zhao, D. Qian, S. Zhang, S. Li, O. Inganas, F. Gao, J. Hou, Adv. Mater. 28 (2016) 4734-4739.

[14] W.R. Mateker, M.D. McGehee, Adv. Mater. (2016) 1603940.

[15] M. Zhang, X. Guo, X. Wang, H. Wang, Y. Li, Chem. Mater. 23 (2011) 4264-4270.

[16] C.M. Cho, Q. Ye, W.T. Neo, T. Lin, J. Song, X. Lu, J. Xu, J. Mater. Sci. 50 (2015) 5856-5864.

[17] W. Zhang, J. Smith, S.E. Watkins, R. Gysel, M. McGehee, A. Salleo, J. Kirkpatrick, S. Ashraf, T. Anthopoulos, M. Heeney, I. McCulloch, J. Am. Chem. Soc. 132 (2010) 11437-11439.

[18] D. Liu, L. Sun, Z. Du, M. Xiao, C. Gu, T. Wang, S. Wen, M. Sun, R. Yang, RSC Adv. 4 (2014) 37934.
[19] X. Liu, Q. Li, Y. Li, X. Gong, S. Su, Y. Cao, J. Mater. Chem. A 2 (2014) 4004-4013.

20] D. Dang, W. Chen, S. Himmelberger, Q. Tao, A. Lundin, R. Yang, W. Zhu, A. Salleo, C. Müller, E. Wang, Adv. Energy Mater. 4 (2014) 1400680.

[21] H. Bai, Y. Wang, P. Cheng, Y. Li, D. Zhu, X. Zhan, ACS Appl. Mater. Interfaces 6 (2014) 8426-8433.

[22] Y. Liu, X. Wan, F. Wang, J. Zhou, G. Long, J. Tian, Y. Chen, Adv. Mater. 23 (2011) 5387-5391.

[23] J. Zhou, X. Wan, Y. Liu, Y. Zuo, Z. Li, G. He, G. Long, W. Ni, C. Li, X. Su, Y. Chen J. Am. Chem. Soc. 134 (2012) 16345-16351.

[24] F. Huang, K.S. Chen, H.L. Yip, S.K. Hau, O. Acton, Y. Zhang, J. Luo, A.K. Jen, J. Am. Chem. Soc. 131 (2009) 13886-13887.

[25] Z. Gu, P. Tang, B. Zhao, H. Luo, X. Guo, H. Chen, G. Yu, X. Liu, P. Shen, S. Tan, Macromolecules 45 (2012) 2359-2366.

[26] H. Tan, X. Deng, J. Yu, B. Zhao, Y. Wang, Y. Liu, W. Zhu, H. Wu, Y. Cao, Macromolecules 46 (2013) 113-118.

[27] P. Shen, H. Bin, L. Xiao, Y. Li, Macromolecules 46 (2013) 9575-9586.

[28] E. Zhu, J. Hai, Z. Wang, B. Ni, Y. Jiang, L. Bian, F. Zhang, W. Tang, J. Phys. Chem. C 117 (2013) 24700-24709.

[29] S.-H. Chan, C.-P. Chen, T.-C. Chao, C. Ting, C.-S. Lin, B.-T. Ko, Macromolecules 41 (2008) 5519-5526.

[30] C.G. Maria, T. Francesca, P. Daniela, B. Chiara, F. Alessandra, Z. Gianni, Macromol. Chem. Phys. 202 (10) (2001).

[31] L.Y. Lin, Y.H. Chen, Z.Y. Huang, H.W. Lin, S.H. Chou, F. Lin, C.W. Chen, Y.H. Liu, K.T. Wong, J. Am. Chem. Soc. 133 (2011) 15822-15825.

[32] J.-M. Jiang, H.-K. Lin, Y.-C. Lin, H.-C. Chen, S.-C. Lan, C.-K. Chang, K.-H. Wei, Macromolecules 47 (2014) 70-78.

[33] C.-P. Chen, Y.-C. Chen, C.-Y. Yu, Polym. Chem. 4 (2013) 1161-1166.

[34] N. Wang, Z. Chen, W. Wei, Z. Jiang, J. Am. Chem. Soc. 135 (2013) $17060-17068$.

[35] M. Wang, H. Wang, T. Yokoyama, X. Liu, Y. Huang, Y. Zhang, T.Q. Nguyen, S. Aramaki, G.C. Bazan, J. Am. Chem. Soc. 136 (2014) 12576-12579.

[36] B. Liu, X. Chen, Y. Zou, Y. He, L. Xiao, X. Xu, L. Li, Y. Li, Polym. Chem. 4 (2013) 470-476. 